\title{
Computing and Information Sciences with changing entry criteria from Non Mathematical Sciences: International Trends and its adoption in Indian Private Universities_-Study of BCA Program
}

\author{
P. K. Paul ${ }^{\text {* }}$, P. S. Aithal ${ }^{2}$, A. Bhuimali ${ }^{3}$ \\ ${ }^{1 *}$ Raiganj University (RGU), West Bengal, India \\ ${ }^{2}$ Vice Chancellor, Srinivas University, Karnataka, India \\ ${ }^{3}$ Vice Chancellor, Raiganj University, West Bengal, India \\ *Corresponding Author: pkpaul.infotech@gmail.com
}

Available online at: www.isroset.org

Received 06/Dec/2017, Revised 22/Dec/2017, Accepted 25/Jan/2018, Online 28/Feb/2018

\begin{abstract}
Computing is an important branch of study due to its importance in different sectors and segments. The academic program in the field of Computing varies country to country. The nomenclatures are also different and organizations and institutes use different nomenclatures in their respective fields. The broadest areas of Computing and Information related areas are called Information Science. In India computing and other science and technology programs are available in both science and engineering track. Computer Science is a theoretical subject and mainly concentrated on the internal affairs of the computer. It is focused with structure and architecture, speed, processing, intelligence etc. It is also dedicated to the hardware centric areas and purely mathematical. Though Computer Application is an applied branch and it is mainly concentrated on software technologies and systems. It is less mathematical and concentrated on internal affairs. It is rather application oriented and focused with the programming technologies. Computer Application comes with two main degrees viz. BCA and MCA. Among these two, MCA is more popular due to its wider acceptance and entry with bachelors in the diverse field of study. Though the eligibility criteria become more flexible these days and universities are moving towards more justified and relevant criteria in this regard. This paper is dedicated to explore this affair in brief. Moreover, the paper is dedicated and focused on private universities in this regard with special reference to changing eligibility criteria, norms, and flexibilities keeping the demand in mind.
\end{abstract}

Keywords- Information, Computing, Information Systems, India, Development, BCA, MCA, Higher Education, Research and Development, Universities.

\section{INTRODUCTION}

Education system is changing rapidly and universities across the globe started many programs and subjects in the field of computing and information. The traditional systems of teaching-learning of Computing and Information field also been changed with additional supplements of newer educational methodologies, teaching techniques etc [1], [5]. In last few years computing and information technology education systems are radically changing. Universities have moved into a centre for excellence apart from traditional engineering colleges [2], [3], [6]. Various emerging technologies and developments such as Cloud Computing, Big Data Technologies, Human Computer Interaction, Usability Engineering, Artificial Intelligence and Robotics included in the curricula in many academic programs in the universities. Indian higher education systems have been significantly developed in recent years and mainly in last few decades. Information Technology as a branch of study popularized in India as well in late 1990's. In India, though interdisciplinary programs viz. Information Science, Information Systems, Information Management, Knowledge Management and Systems are absent but in specific sectors and workplaces, their requirements are enormous [3], [4], [5]. Computer Application branch developed in the 1980s with the solid aim and objective of promoting applications of computing with adequate software systems. In recent past apart from funded universities, private universities are also doing well in terms of new age programs, subjects, teaching methods etc.

\section{ObJeCtive AND Methods}

The present paper is theoretical in nature and it is also interdisciplinary due to its concentration in education, and information technology. It mainly lies in following aim and objectives in brief- 
- To learn about the higher education systems in India with reference to the universities in a brief manner.

- To know about the degrees and programs available in the field of information and computing in international and Indian context.

- To learn about the nature and characteristics of computing and information related field at a glance; both in Indian and International context.

- To dig out the general criteria for the eligibility of Computer Application programs with reference to BCA and MCA degrees.

- $\quad$ To find out the changing eligibility criteria of BCA program specifically in the private universities in India.

- To learn about the need of changing eligibility criteria in BCA programs with its proper justification.

- To learn about the emerging programs in the BCA program with reference to the major/ honors/ specializations.

\section{COMPUTING AND INFORMATION AS A FIELD}

Computing and Information sector has grown vast enough from the circle of Computing among the fields and disciplines few important are Computer Science, Computer Engineering, Computer Application; whereas in Information centric segment few fields of studies/ technologies are Information Technology, Information Science, Information Systems, Information Management etc [5], [10], [11]. Even apart from these few combined subjects include Computer Science and Engineering, Computer and Information Science, Information Science and Technology, Information Systems and Technology etc.

Computer Science is a field of study mainly concentrated on internal affairs of computing with a due concentration on study, designing, evaluation of Computer Systems. It is closely associated with the hardware and computer architecture, algorithm, microprocessor etc. Moreover, it additionally deals with software technologies. The core concentration of designing and development is called Computer Engineering. Though, the combination of both the concepts appears as Computer Science and Engineering. Due to increasing computing applications and its requirement another domain lead the development i.e. Computer Application. The domain is also concentrated on Software Technologies as well [6], [10], [12].

Information Technology is another applied science domain concentration with applied technologies dealing with information such as Database Technologies, Networking Technologies, Web Technologies, Multimedia Technology apart from Software Technologies. Internationally this field is gained popularity as an alternative to Computer Science and related fields as an alternative applied field [7], [9]. Though, additional components of Management and Social Sciences within Information Technology lead the concepts and development of Information Science. Similar to Information Science another applied domain concentration on applications of Information Technologies and Computing in the business and organizations including IT organizations and policies called as Information Systems.

\section{Degrees in Computing and Information: World Vs. India}

Internationally Computing and Information related subjects viz. Computer Science, Computer Engineering etc are available as BS (Bachelor of Science) degree/ MS (Master of Science) degrees mainly, except very few B.Engg. (Bachelor of Engineering) and M.Engg. (Master of Engineering)/ BTech (Bachelor of Technology) and MTech (Master of Technology) in these subjects. Similarly the domains of Information centric fields of studies/ viz. Information Technology, Information Science, Information Systems, Information Management are also available with BS and MS Degree. While few offered Engineering degrees mentioned previously in mainly the subject of IT.

In India, in Computing segment, all these subjects are popular and started in academia with BSc and MSc (instead of BS/MS), and BTech and MTech. Additionally, another domain had been conceptualized, started, and still running i.e. Computer Application. The subject mainly available with the degrees of BCA and MCA, and still available in India only. As far as Information related field only Information Technology mainly available and popular with BSc and MSc (instead of BS/MS), and BTech and MTech degrees. Though, Information Science is available only in about 10 Institutes in India with MSc degree. The subjects like Information Systems, Information Management etc not yet started in the Indian academia.

\section{BCA Program: AN OVERVIEW}

The branch initially started in 1980's as an alternative to Computer Science. While internationally academic institutes were moved upon Information Technology branch as an alternative but initially Computer Application branch conceptualized, developed, and started in India. First time the branch started with the nomenclature and degree 'Master of Computer Application' and abbreviated as MCA. While existing program such as MSc-Computer Science concentrated on theoretical foundations and mathematical concentration the MCA was started with applied nature and focused on software technology. It is moreover concentrated for the development workers in the software industry. The eligibility criterion for the MCA is also different than MScCS program. The MCA is open to all kind of graduates and not only students from non pure science and bio sciences but 
also students from humanities and commerce. Hence within a stipulated time, the program got reputation in academia and industry due to ready professionals in software industry; while existing Computer Science was not prominent in software and industry directly.

Similar to the MCA program another one started later on at the Bachelors level with the nomenclature and degree of BCA. Naturally, unlike existing program BSc-CS it was started an arena to the other streams students as an entry route for the Computing and IT jobs etc.

\section{BCA and Changing Eligibility: Why and How?}

The BCA (Bachelor of Computer Application) program is also three years based and open to the $10+2$ Candidates. Though while most of the existing programs (BSc-CS) open for the $10+2$ with Science as like MCA program the BCA is also open to all 10+2 Candidates. But similar to MCA condition of at least one paper on Mathematics is common for the entry of BCA program. Though it is fact that initially when MCA program was started there was no paper related to the Computer Science/etc. Hence due to logical concentration and requirement universities were asked (and still common in AICTE guidelines) at-least one paper on Mathematics at Bachelors level or at $10+2$. Similar to this in the BCA program the eligibility also remains same. Though today Computer and related subjects are common and widely available at 10+2 level and thus as an alternative of Mathematics many universities allow Computer/related paper as an entry to the program of study. Though, the concept of allowing MCA for any Bachelors degree holders with Computer/related subjects is still limited [8], [12].

Even many universities in recent passed also waive the norms Computer and IT related subject at $10+2$ as well. Such universities allow candidates with a perception that the components of computing offered at $10+2$ may be offered in the BCA program initially. Such norms basically established as per latest international trend of flexible eligibility and this is also duly approved and accepted in the industries and organizations in India. Hence by this way, $10+2$ from diverse discipline can be a part of BCA program for the creation of Digital and IT Society and Economy.

\section{BCA and Private Universities in India: A Case}

Today a large number of private universities are established Pan India basis and doing well in a different segment. Private universities enjoy the similar power to confer the awards and degrees to the students and professionals. BCA Program as a university degree may be offered by the own unit of the university or by the affiliated colleges. As the Private Universities are autonomous in nature hence they offer the programs in their own units and bodies and thus today many private universities have started the program leading to BCA. India holds a total 279 universities in its bag in private segment and out of which a large number are professional in nature. A Study already conducted and reported shows that among the Indian private universities total 171 are offering the program.

Table: 1- BCA Program in Private Universities (as on Oct. 2017) (Paul. et.al, 2018)

\begin{tabular}{|c|c|c|c|}
\hline $\begin{array}{l}\text { Serial } \\
\text { No. }\end{array}$ & States & $\begin{array}{c}\text { No. of } \\
\text { Universities }\end{array}$ & BCA \\
\hline 1 & $\begin{array}{l}\text { Arunachal } \\
\text { Pradesh }\end{array}$ & 7 & 04 \\
\hline 2 & Assam & 5 & 04 \\
\hline 3 & Bihar & 2 & 01 \\
\hline 4 & Chhattisgarh & 9 & 07 \\
\hline 5 & Gujarat & 30 & 12 \\
\hline 6 & Haryana & 20 & 12 \\
\hline 7 & $\begin{array}{l}\text { Himachal } \\
\text { Pradesh }\end{array}$ & 17 & 10 \\
\hline 8 & Jharkhand & 7 & 03 \\
\hline 9 & Karnataka & 14 & 05 \\
\hline 10 & Meghalaya & 8 & 05 \\
\hline 11 & Mizoram & 1 & 01 \\
\hline 12 & Madhya Pradesh & 24 & 17 \\
\hline 13 & Maharashtra & 9 & 06 \\
\hline 14 & Manipur & 1 & 01 \\
\hline 15 & Nagaland & 3 & 02 \\
\hline 16 & Odisha & 4 & 01 \\
\hline 17 & Punjab & 15 & 12 \\
\hline 18 & Rajasthan & 46 & 26 \\
\hline 19 & Sikkim & 5 & 04 \\
\hline 20 & Tripura & 1 & 01 \\
\hline 21 & Uttar Pradesh & 29 & 22 \\
\hline 22 & Uttrakhand & 13 & 09 \\
\hline 23 & West Bengal & 9 & 06 \\
\hline \multicolumn{2}{|c|}{ Grand Total } & 279 & 171 \\
\hline
\end{tabular}

Importantly a large number of universities in this category are situated in Rajasthan, Gujarat and Uttar Pradesh with number (forty six) 46, (thirty) 30, and (twenty nine) 29 respectively. And as far as BCA degree is concerned a large among the universities in this category are from Rajasthan, Uttar Pradesh, and Madhya Pradesh. While Gujarat and Haryana both hold good number of universities but a total number 12 and 12 respectively offering BCA program from the circle (refer Fig: 1). 


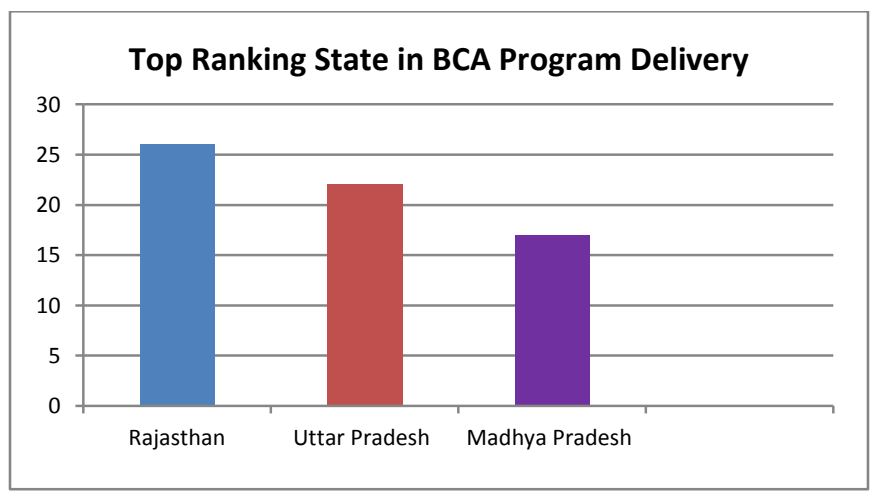
Fig: 1-Top three States in offering BCA program in
Private Universities

The changing eligibility of BCA is also important to notice. As per the study, it is noticed that a total 107 (out of 171 BCA offering Universities) universities are offering BCA program with $10+2$ in any stream and in this regard the first state is Rajasthan with 20 number of BCA programs [6]. While the rank of the second, third and fourth goes to the state of Punjab and Madhya Pradesh respectively, a detailed picture with nationwide statistics is given in Table: 2 herewith.

However, it is important to note that some of the universities also offered multiple numbers of BCA programs with different concentration such as-

- BCA

- $\quad$ BCA (Hons)

- BCA (Specialization/ Concentration) etc

It is worthy to note that the BCA (Honors) with additional electives or higher credits in few universities and BCA with specialization is devoted to the focus on any particular components of Computing and Information Technologies. Hence the table showing flexibility not conferred a number of BCA program rather on a number of universities adopted and started flexibility more specifically.

Table: 2- BCA Program in Private Universities with Flexible eligibility

\begin{tabular}{|c|l|c|c|}
\hline $\begin{array}{c}\text { Serial } \\
\text { No. }\end{array}$ & \multicolumn{1}{|c|}{ States } & $\begin{array}{c}\text { No. of } \\
\text { Universities }\end{array}$ & $\begin{array}{c}\text { No. } \\
\text { universities } \\
\text { having } \\
\text { Flexible entry } \\
\text { in BCA } \\
\text { programs }\end{array}$ \\
\hline $\mathbf{1}$ & $\begin{array}{l}\text { Arunachal } \\
\text { Pradesh }\end{array}$ & 7 & 3 \\
\hline $\mathbf{2}$ & Assam & 5 & 2 \\
\hline $\mathbf{3}$ & Bihar & 2 & Nil \\
\hline $\mathbf{4}$ & Chhattisgarh & 9 & 4 \\
\hline
\end{tabular}

\begin{tabular}{|c|l|c|c|}
\hline $\mathbf{5}$ & Gujarat & 30 & 9 \\
\hline $\mathbf{6}$ & Haryana & 20 & 6 \\
\hline $\mathbf{7}$ & $\begin{array}{l}\text { Himachal } \\
\text { Pradesh }\end{array}$ & 17 & 8 \\
\hline $\mathbf{8}$ & Jharkhand & 7 & 2 \\
\hline $\mathbf{9}$ & Karnataka & 14 & 5 \\
\hline $\mathbf{1 0}$ & Meghalaya & 8 & 4 \\
\hline $\mathbf{1 1}$ & Mizoram & 1 & 1 \\
\hline $\mathbf{1 2}$ & Madhya & 24 & 10 \\
\hline $\mathbf{1 3}$ & Pradesh & & 4 \\
\hline $\mathbf{1 4}$ & Manarashtra & 9 & 1 \\
\hline $\mathbf{1 5}$ & Nagaland & 1 & Nil \\
\hline $\mathbf{1 6}$ & Odisha & 4 & 1 \\
\hline $\mathbf{1 7}$ & Punjab & 15 & 11 \\
\hline $\mathbf{1 8}$ & Rajasthan & 46 & 20 \\
\hline $\mathbf{1 9}$ & Sikkim & 5 & Nil \\
\hline $\mathbf{2 0}$ & Tripura & 1 & 1 \\
\hline $\mathbf{2 1}$ & Uttar Pradesh & 29 & 9 \\
\hline $\mathbf{2 2}$ & Uttrakhand & 13 & 4 \\
\hline $\mathbf{2 3}$ & West Bengal & 9 & 2 \\
\hline \multicolumn{2}{|c|}{ Grand Total } & $\mathbf{2 7 9}$ & $\mathbf{1 0 7}$ \\
\hline
\end{tabular}

Among the Universities offers two BCA Programs include Marwadi University; Gujarat, UKA Tarsadia University; Gujarat, ITM University; Madhya Pradesh, These universities offer one general BCA and another with tag BCA (Honors). While Srinivas University; Karnataka offers Three BCA Program with Major and Concentration.

The details of state-wise universities offer BCA programs and universities with flexible BCA program for any $10+2$ students irrespective of the requirement of Mathematics/ related subjects or Computer/ related subjects depicted in Table: 3 [6]. The States with good percentage of BCA Programs compare to flexible BCA programs are include-

- Arnunachal Pradesh

- Rajasthan

- Meghalaya

- Madhya Pradesh.

However in few states number of BCA program is good but they do not yet majorly taken initiative for the program of flexibilities; among these states, few important are include-

- Maharashtra

- Nagaland

- Sikkim etc 
Table: 3- BCA Program with normal and Flexible eligibility

\begin{tabular}{|c|l|c|c|c|}
\hline $\begin{array}{c}\text { Seria } \\
\text { I No. }\end{array}$ & \multicolumn{1}{|c|}{ States } & $\begin{array}{c}\text { No. of } \\
\text { Universiti } \\
\text { es }\end{array}$ & $\begin{array}{c}\text { No. of } \\
\text { universiti } \\
\text { es with } \\
\text { BCA } \\
\text { programs }\end{array}$ & $\begin{array}{c}\text { No. } \\
\text { universiti } \\
\text { es having } \\
\text { Flexible } \\
\text { entry in } \\
\text { BCA } \\
\text { programs }\end{array}$ \\
\hline $\mathbf{1}$ & $\begin{array}{l}\text { Arunachal } \\
\text { Pradesh }\end{array}$ & 7 & 04 & 3 \\
\hline $\mathbf{2}$ & Assam & 5 & 04 & 2 \\
\hline $\mathbf{3}$ & Bihar & 2 & 01 & Nil \\
\hline $\mathbf{4}$ & $\begin{array}{l}\text { Chhattisga } \\
\text { rh }\end{array}$ & 9 & 07 & 4 \\
\hline $\mathbf{5}$ & Gujarat & 30 & 12 & 9 \\
\hline $\mathbf{6}$ & Haryana & 20 & 12 & 6 \\
\hline $\mathbf{7}$ & $\begin{array}{l}\text { Himachal } \\
\text { Pradesh }\end{array}$ & 17 & 10 & 8 \\
\hline $\mathbf{8}$ & Jharkhand & 7 & 03 & 2 \\
\hline $\mathbf{9}$ & Karnataka & 14 & 05 & 5 \\
\hline $\mathbf{1 0}$ & Meghalaya & 8 & 05 & 4 \\
\hline $\mathbf{1 1}$ & Mizoram & 1 & 01 & 1 \\
\hline $\mathbf{1 2}$ & $\begin{array}{l}\text { Madhya } \\
\text { Pradesh }\end{array}$ & 24 & 17 & 10 \\
\hline $\mathbf{1 3}$ & $\begin{array}{l}\text { Maharashtr } \\
\text { a }\end{array}$ & 9 & 06 & 4 \\
\hline $\mathbf{1 4}$ & Manipur & 1 & 01 & 1 \\
\hline $\mathbf{1 5}$ & Nagaland & 3 & 02 & Nil \\
\hline $\mathbf{1 6}$ & Odisha & 4 & 01 & 1 \\
\hline $\mathbf{1 7}$ & Punjab & 15 & 12 & 11 \\
\hline $\mathbf{1 8}$ & Rajasthan & 46 & 26 & 20 \\
\hline $\mathbf{1 9}$ & Sikkim & 5 & 04 & Nil \\
\hline $\mathbf{2 0}$ & Tripura & 1 & 01 & 1 \\
\hline $\mathbf{2 1}$ & $\begin{array}{l}\text { Uttar } \\
\text { Pradesh }\end{array}$ & 29 & 22 & 9 \\
\hline $\mathbf{2 2}$ & Uttrakhand & 13 & 09 & 4 \\
\hline $\mathbf{2 3}$ & $\begin{array}{l}\text { West } \\
\text { Bengal }\end{array}$ & 9 & 06 & 2 \\
\hline & Grand & $\mathbf{2 7 9}$ & $\mathbf{1 7 1}$ & $\mathbf{1 0 7}$ \\
\hline
\end{tabular}

\section{BCA with Major/Honors/Specialization with Flexible Eligibility!}

The new age also lies in BCA Degrees! Initially, Bachelors degrees such as BA, BSc, BCom were started in general basis but the gradual development in the higher education systems, infrastructure, educational planning have been changed and forced towards implementation and initiation of BA, BSc, BCom with Honors/ Major. But as far as BCA

degree is concerned it is still treated as the equivalent of BSc-Computing (Honors). In such similar programs apart from Computer (i.e. Honors/ Major) an amount restricted in other subjects; while in BCA program full concentration is on Computing and IT related subject. The full-fledged degree $\mathrm{BCA}$ is concentrated on Computer Application. The field Computer Application is today fast and vast enough and thus there is a potentiality to offer a concentration within Computer Application (such as in Arts, for example, a Major in Political Science) viz. Computer Application with Major in Networking Technology.

\section{Findings}

- Computer Application is an applied science branch concentrated on software technologies and responsible for the creation of manpower in the field of the Software industry.

- Computer Application is fully dedicated to the students from diverse background whereas other branches viz. Computer Science, Computer Engineering mainly restricted to the related or relevant (mainly Mathematical Sciences) subject holders.

BCA Entry: Traditional \& Flexibile

- Entry with $10+2$ with Mathematical or Related Subject Entry with $10+2$ in Any Stream

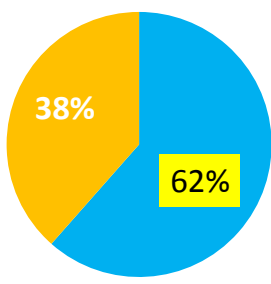

Fig: 2-Sharing of BCA Degree Entry with traditional Related/ Relevant paper \& $10+2$ any stream

- Internationally as an Applied Science subject Information Technology was started with the core concentration of Networking Technology, Database Technology, Multimedia Technology, Software Technology etc. Hence it is broader than Computer Application domain (with the program BCA/MCA) which is conceptualized, practiced and still available in India.

- Computer Application initially offered in the affiliated colleges under the State University up to late 1990s; though since 2000s the program started in affiliated colleges under the Technological Universities in many states. After 2010s and later on the craze of BCA has been started in Private and Deemed University; due to in-house operation, 
internship and placement opportunities, industry linkage etc.

- Initially, Computer Application programs opened for diverse background candidates with at least one paper/course on Mathematics or similar subjects. Gradually the initiation of Computer and related papers lead the concept of accepting candidates with Computer as a paper/course as well for the entry to the BCA including private universities.

- India holds about 280 universities with self financing nature and among these universities, 171 have BCA programs while 107 offering flexible programs with $10+2$ in any stream (Refer Fig: 2).

- The craze of starting BCA (Honors) is increasing day by day due to enhancement and implication of the education models and regulations etc.

- Super Specialty programs have been started in some of the private universities while among these Srinivas University, Karnataka prime one as per this study.

\section{Future Requirement}

- As per this study, it has been noted that a large number of universities now accepting and allowing BCA not only Computer related papers but also $10+2$ in any Stream. Though still among the Private Universities, $62 \%$ concentrated with related/ relevant papers. The study noted that both are getting equal opportunities in the industry and organizations; thus remaining universities may also implement the same policy.

- Many universities though started allowing BCA Degree entry with $10+2$ in any stream but not prepared initial syllabus with basics of computing/ prerequisite; which are essential and important.

- $\quad$ BCA programs may be implemented as per industry relevance and in collaboration with the industry and thus industry and academia both side sessions/ lectures may be offered.

- The domain centric Computing and IT may be offered in the traditional BCA Degree for solid and realistic manpower delivery.

\section{CONCLUSION}

Computer Applications is conceptualized, started and developed in India with leading to the degrees of BCA and MCA. The move of starting MCA was good enough, as the program started for the diverse background Bachelors degree holders. Though, the condition of Mathematics as a paper/course still mandatory for the colleges under AICTE. The craze of private universities leads a new type of programs, educational models, and nomenclatures etc. As a result of BCA program also traditional eligibility initially changed with the alternative of Computing paper instead of Mathematics. The second innings of 'criteria change' is purely based on the international trend in which the required paper (Computing/Mathematics) offered at the beginning / parallel to the program. The private universities and other types are also doing well in respect of new educational model etc. The super specialty programs, major and concentration based move at the BCA level also a healthy deal and here much industry integration etc may be better for development of skillful and relevant manpower.

\section{REFERENCE}

[1] Desai, S., \& Kulkarni, V. (2008). Changing educational inequalities in India in the context of affirmative action. Demography, 45(2), 245-270.

[2] Gereffi, G., Wadhwa, V., Rissing, B., \& Ong, R. (2008). Getting the numbers right: International engineering education in the United States, China, and India. Journal of Engineering Education, 97(1), 13-25.

[3] Gupta, D., \& Gupta, N. (2012). Higher education in India: structure, statistics and challenges. Journal of education and Practice, 3(2).

[4] Bhattacharya, I., \& Sharma, K. (2007). India in the knowledge economy-an electronic paradigm. International Journal of Educational Management, 21(6), 543-568.

[5] Paul, P.K. and Bhuimali, A. and Aithal, P. S., (2017). Indian Higher Education: With Slant to Information Technology - a Fundamental Overview. International Journal on Recent Researches In Science, Engineering \& Technology, 5(11), 31-50.

[6] Paul, P.K. and Aithal, P. S. (2017) Bachelor of Computer Applications (BCA): An Applied Science Program into a New Direction? Educational Quest: An Int. J. of Education and Applied Social Science, 8(4), 1-9.

[7] Paul, P.K., Aithal, P. S., Bhuimali, A., \& Kumar, K. (2017). Emerging Degrees and Collaboration: The Context of Engineering Sciences in Computing \& IT-An Analysis for Enhanced Policy Formulation in India. International Journal on Recent Researches In Science, Engineering \& Technology, 5(12), 13-27.

[8] Paul, P.K., Bhuimali, A., Aithal, P. S. \& Rajesh, R., (2017). Bachelor's Degree in Computing and Allied Fields in India Emphasizing Private Universities - A Study of Science Platform (BCA \& BSc). International Journal on Recent Researches in Science, Engineering \& Technology, 5(12), 1-12.

[9] Tate, D. S., \& Schwartz, C. L. (1993). Increasing the retention of American Indian students in professional programs in higher education. Journal of American Indian Education, 21-31.

[10] Tayade, M. C., \& Kulkarni, N. B. (2011). The Interface of technology and medical education in india: current trends and scope. Indian Journal of Basic \& Applied Medical Research, 1(1), 8-12.

[11] Tijerina, K. H., \& Biemer, P. P. (1988). The Dance of Indian Higher Education: One Step forward, Two Steps back. Educational Record, 68(4), 86-91.

[12] Umashankar, V., \& Dutta, K. (2007). Balanced scorecards in managing higher education institutions: an Indian perspective. International Journal of Educational Management, 21(1), 54-67. 